\title{
Approximate Entropy in Analysis of Cardiovascular Response to Lower Body Negative Pressure Test
}

\author{
Agnieszka Strok ${ }^{1}$, Gerard Cybulski ${ }^{1}$, Anna Gąsiorowska ${ }^{2}$, Wiktor Niewiadomski $^{2}$, Anna Strasz ${ }^{3}$ \\ ${ }^{1}$ Institute of Metrology and Biomedical Engineering, Department of Mechatronics, \\ Warsaw University of Technology, Warsaw, Poland \\ ${ }^{2}$ Department of Applied Physiology, Mossakowski Medical Research Centre, \\ Polish Academy of Sciences, Warsaw, Poland \\ ${ }^{3}$ University of Mazovia in Warsaw, Poland
}

\begin{abstract}
The aim of the study was to evaluate the changes in approximate entropy (ApEn), used to quantify the amount of regularity and the unpredictability of fluctuations over hemodynamic traces before $(0 \mathrm{mmHg})$ lower body negative pressure $(L B N P)$ and during the first part of the test $(-15 \mathrm{~mm} \mathrm{Hg})$ in 13 subjects with high (HT) and 11 of low (LT) tolerance to LBNP. We intended to know if ApEn calculated for HT and LT groups are significantly different.

24 healthy, untrained male subjects (age:20.8 \pm 0.9 yrs, height: $176.9 \pm 4.3 \mathrm{~cm}$, body mass: $74.2 \pm 7.1 \mathrm{~kg})$ were submitted to graded LBNP (-15, -30 and $-50 \mathrm{mmHg}$ ) lasting 10 minutes for each load.

The length of RR interval (RR), stroke volume (SV) and ejection time (ET) were determined basing on ECG and first derivative $(d z / d t)$ of impedance cardiography (ICG) traces. Analysis were carried out for unprocessed $d z / d t$ waveform and for hemodynamic parameters time series $(R R, \quad S V$, ET) by determining ApEn using Pincus approach.

No differences in ApEn were found between $L T$ and $H T$ for raw dz/dt traces and RR, SV, ET time series. ApEn for RR, SV and ET were similar in both periods. ApEn seems to be not suitable for predicting the outcome of LBNP test.
\end{abstract}

\section{Introduction}

\subsection{Motivation}

Application of lower body negative pressure (LBNP) causes a shift of fluid from the upper body to lower extremities resulting in central hypovolemia. This might lead to reduction of cerebral blood flow and, finally, possibility of syncope. LBNP has been applied for evaluation of the compensatory ability of the cardiovascular control systems [1]. This research test has been used in space and aviation medicine to study orthostatic intolerance after space flight and effects of microgravity induced by bed rest or vertical acceleration in aircrafts [2].

Cooke et al. suggested that LBNP may be also used to identify persons who will progress to shock under condition of haemorrhagic trauma [3]. Convertino et al. proposed an estimation of the physiological reserve for individual soldiers [4]. Using LBNP it is possible to qualify people to the low tolerance (LT) group and high tolerance (HT) for haemodynamic changes. The assignment of subjects to a particular group is carried out using the LBNP test, which allows to simulate the blood loss of wounded soldier. The whole test lasts up to about 50 minutes until the moment of hemodynamic instability is reached, which allows to determine the Compensatory Reserve Index (CRI) [5, 6].

We were interested if the measures of complexity, e.g. approximate entropy (ApEn) might help to classify subjects with high and low tolerance basing on the hemodynamic response to LBNP test.

\subsection{The aim of the study}

The aim of this study was to evaluate the changes in approximate entropy (ApEn) calculated for hemodynamic traces before $(0 \mathrm{mmHg})$ and during the first part of the LBNP test $(-15 \mathrm{~mm} \mathrm{Hg})$ in 13 subjects with high (HT) and 11 of low (LT) tolerance to LBNP.

Buszko et al. [7], who analysed the hemodynamic response to tilt test, found that for all analysed signals, the lowest entropy values in the pre-syncope phase were observed at the moment when loss of consciousness occurred. Inspired by their findings we hoped that the ApEn might be also different in LT and HT groups. 


\section{Material and methods}

To estimate ApEn in analysis of cardiovascular response to LBNP test, we used data from our impedance cardiography signal database. These data were originally collected for other studies in order to analyse cardiac haemodynamic response to LBNP in young subjects before and after endurance physical training who were exposed to 3-day bedrest [8]. This analysis were not included into final papers $[8,9]$.

\subsection{Subjects and procedure}

24 healthy, untrained male subjects (age:20.8 $\pm 0.9 \mathrm{yrs,}$ height: $176.9 \pm 4.3 \mathrm{~cm}$, body mass: $74.2 \pm 7.1 \mathrm{~kg}$ ) were exposed to graded LBNP: $10 \mathrm{~min}$ at $-15 \mathrm{mmHg}, 10 \mathrm{~min}$ at $-30 \mathrm{mmHg}$ and $10 \mathrm{~min}$ at $-50 \mathrm{mmHg}$ or until onset of presyncopal symptoms. Also signals were recorded during 10 minutes of the recovery period with no underpressure. The presyncope symptoms and signs include: light headedness, nausea, sweating, narrowing of vision and rapid drop of systolic blood pressure by more than $20 \mathrm{mmHg}$ or bradycardia. The length of RR interval (RR), heart rate (HR) stroke volume (SV), cardiac output (CO) and ejection time (ET) were determined basing on ECG and first derivative (dz/dt) of impedance cardiography (ICG) traces.

\subsection{Methods and instrumentation}

We used the wearable, ambulatory impedance cardiography recorder (Reomonitor), described earlier $[10,11]$. The device was constructed for non-invasive acquisition of central haemodynamic data during everyday activity. The analogue part of the Reomonitor consists of a one-channel ECG and a miniaturized impedance cardiograph. Changes in the thoracic impedance, reflecting $\mathrm{SV}$, were estimated using the tetrapolar method. An alternating current (with an effective amplitude of $1 \mathrm{~mA}$ and a frequency of $100 \mathrm{kHz}$ ) oscillated between the application electrodes while the voltage (reflecting the impedance) was measured between the receiving electrodes. ECG and the first derivative of the impedance cardiography signal $(\mathrm{dz} / \mathrm{dt})$ were sampled at $200 \mathrm{~Hz}$ with 8 -bit resolution. Stroke volume was estimated using the Kubicek formula [12]. The validity and reliability of impedance cardiography have been reviewed in numerous studies [13, 14]. The Reomonitor system was verified using echocardiography in both the supine and tilted positions [11].

\subsection{Data analysis}

The dedicated computer program was written in Python environment. It allows to visualize the waveforms of ECG and ICG signals and allow the "beat-to-beat" variability presentation of the main hemodynamic indices (RR, SV, ET, CO) calculated before and during the LBNP test.

In 1991 Pincus [15] proposed the concept of Approximate Entropy (ApEn) as a quantitative measure of the complexity: the greater irregularity and unpredictability of the system, the greater is the value of entropy. Calculation of ApEn is based on measuring the likelihood that similar sequences of points in a time series remain similar for incremented sequences. The algorithm for ApEn calculation is described in the literature [15, 16, 17, 18]. Calculations of ApEn in our program are performed basing on the algorithm proposed in the literature $[15,16]$.

The analysed data contained waveforms of 11 people belonging to the LT group and 13 to HT. ApEn analysis was carried out for unprocessed dz/dt waveform and for hemodynamic parameters time series (RR, SV, ET).

Artefacts were removed from the analysis basing on the clearly defined criteria for each variable, determined mainly using physiological and pathophysiological ranges.

\section{Results}

\subsection{ICG raw signal analysis}

ApEn of $\mathrm{dz} / \mathrm{dt}$ raw signal in no load $(0 \mathrm{mmHg})$ period was 0.23 (range:0.18-0.33) and $0.24(0.21-0.29)$ (NS), in LT and HT, respectively.

For the load of $-15 \mathrm{mmHg}$ the ApEn was 0.25 (0.16$0.40)$ and $0.25(0.18-0.34(\mathrm{NS})$, respectively.

\subsection{Hemodynamic data analysis}

For SV the ApEn at $0 \mathrm{mmHg}$ was 1.15 (range:0.87$1.30)$ and $1.13(0.87-1.30)$ (NS), in LT and HT, respectively. During the $-15 \mathrm{mmHg}$ period the results were 1.36 (1.27-1.46) (LT) and 1.31 (1.18-1.49) (HT).

At rest data for ET were: $1.07(0.68-1.35)(\mathrm{LT})$ and 1.05 (0.81-1.24) (HT), whereas in $-15 \mathrm{mmHg}$ load: 1.21 (0.98-1.43) (LT) and 1.25 (0.98-1.34) (HT).

At rest data for RR were:1.06 (0.76-1.19) (LT) and $1.05(0.99-1.18)$ (HT), whereas in $-15 \mathrm{mmHg}$ load: 1.14 (0.82-1.36) (LT) and 1.15 (0.91-1.40) (HT).

Figure 1. presents the example of beat-to-beat changes in HR, SV and CO indices during the whole LBNP test performed in person from LT group. The beginning of the $-15 \mathrm{mmHg}$ is located around $300^{\text {th }}$ second. The -30 $\mathrm{mmHg}$ load started around $900^{\text {th }}$ second. The last load of $50 \mathrm{mmHg}$ began at $1500^{\text {th }}$ second and finished at around 1800 second. 

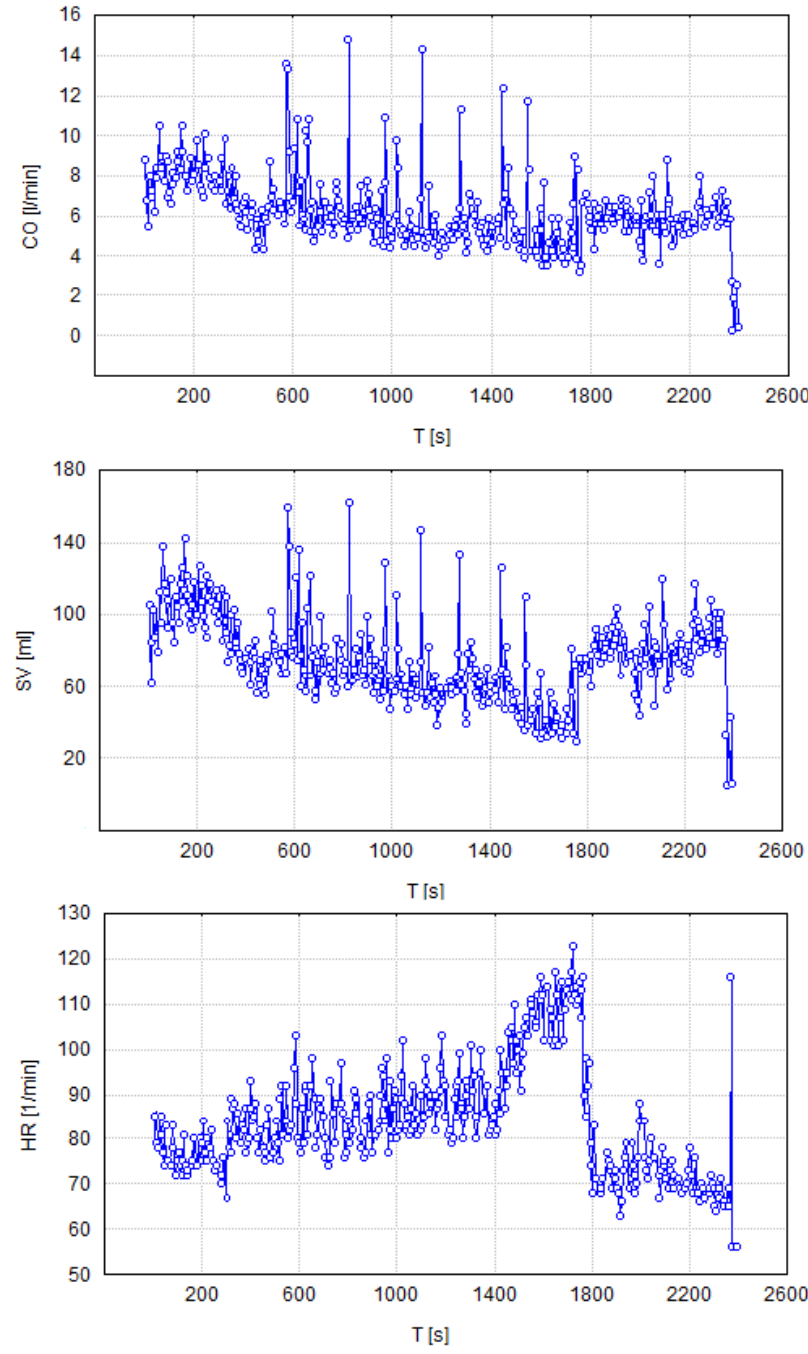

Figure 1. Example (LT group) of beat-to-beat changes in HR, SV and CO indices during the LBNP test. The beginning of the $-15 \mathrm{mmHg}$ is located around $300^{\text {th }}$ second. The underpressure was withdrawn at around $1800^{\text {th }}$ second.

\section{Discussion and conclusions}

Some other papers have shown promising results regarding the possibility of prediction the outcome of tilt test basing on analysis of hemodynamics response [7, 19]. However, no differences in ApEn were found between LT and HT for raw dz/dt traces and RR, SV, ET time series. ApEn for RR, SV and ET were similar in both groups. ApEn calculated for the first phase of LBNP $(-15 \mathrm{mmHg}$ load) seems to be not suitable for predicting the outcome of LBNP test.

Perhaps, the ApEn analysis performed for other loads (-30 $\mathrm{mmHg}$ or $-50 \mathrm{mmHg}$ ) might bring more promising results. Even so, it could not be considered as an "early detection" tool for low tolerance to LBNP.

\section{Acknowledgements}

The study was supported by the research programs of institutions the authors are affiliated with. We also thank all people helping us to acquire data for principal studies $[8,9]$.

\section{References}

[1] Stevens PM, Lamb LE. Effects of lower body negative pressure on the cardiovascular system. Am J Cardiol 1966; 16: 506 - 515.

[2] Convertino VA. Lower body negative pressure as a tool for research in aerospace physiology and military medicine. $\mathrm{J}$ Gravit Physiol 2001;8:1-14.

[3] Cooke WH, Ryan KL, Convertino VA. Lower body negative pressure as a model to study progression to hemorrhagic shock in humans. J Appl Physiol 2004; 96: 1249 - 1261.

[4] Convertino VA, Ludvig DA, Cooke WH. Stroke volume and sympathetic responses to lowerbody negative pressure reveal new insight into circulatory shock in humans. Autonom Neurosci Basic a Clin 2004; 111: 127-134.

[5] Convertino V., Grudic G., Mulligan J., Moulton S., Estimation of individual-specific progression to impending cardiovascular instability using arterial waveforms, Journal of Applied Physiology, 2013 Oct 15;115(8):1196-202.

[6] Convertino A., Wirt M., Glenn J., Lein B., The compensatory reserve for early and accurate prediction of hemodynamic compromise: a review of the underlying physiology, Shock. 2016 Jun;45(6):580-90.

[7] Buszko K., Piątkowska A., Koźluk E., Opolski G., Entropy in Investigation of Vasovagal Syndrome in Passive Head Up Tilt Test, Entropy, 2017;19(5): 236.

[8] Gąsiorowska A, Nazar K, Mikulski T, Cybulski G, Niewiadomski W, Smorawinski J, Krzeminski K, Porta S, Kaciuba-Uscilko H. Hemodynamic and neuroendocrine predictors of lower body negative pressure (LBNP) intolerance in healthy young men. J Physiol Pharmacol 2005, 56 (2): 179-193.

[9] Smorawinski J, Młynarczyk C, Ziemba AW, Mikulski T, Cybulski G, Grucza R, Nazar K, Kaciuba-Uscilko H, Greenleaf JE. Exercise training and 3-day head down bed rest deconditioning: exercise thermoregulation. J Physiol. Pharmacol., 2005, 56, 1, 101-110.

[10] Cybulski G, Książkiewicz A, Łukasik W, Niewiadomski W, Pałko T. Ambulatory monitoring device for central hemodynamics and ECG signals recording on PCMCIA flash memory cards, Computers in Cardiology 1995;22:505-7.

[11] Cybulski G, Michalak E, Koźluk E, Piątkowska A, Niewiadomski W. Stroke volume and systolic time intervals: beat-to-beat comparison between echocardiography and ambulatory impedance cardiography in supine and tilted positions. Medical and Biological Engineering and Computing 2004;42:707-11.

[12] Kubicek WG, Karnegis JN, Patterson RP, Witsoe DA, Mattson RH. Development and evaluation of an impedance 
cardiac output system. Aerospace Medicine 1966;37:120812.

[13] Cybulski G, Strasz A, Niewiadomski W, Gąsiorowska A. Impedance cardiography: Recent advancements. Cardiol J 2012;19(5):550-6.

[14] Fellahi JL, Fischer MO. Electrical bioimpedance cardiography: an old technology with new hopes for the future. J Cardiothorac Vasc Anesth 2014;28(3):755-60.

[15] Pincus, S.M. Approximate entropy as a measure of system complexity. Proc. Natl. Acad. Sci. USA 1991, 88, 2297 2301.

[16] Pincus, S.; Huang, W. Approximate entropy-statistical properties and applications. Commun. Stat. Theory Methods 1992, 21, 3061-3077.

[17] Chon K., Scully C.G., Lu S., Approximate entropy for all signals, IEEE Eng Med Biol Mag. 2009 Nov-Dec;28(6):1823.

[18] Richman, J.S.; Moorman, J.R. Physiological time-series analysis using approximate entropy and sample entropy. Am. J. Physiol. Heart Circ. Physiol. 2000, 278, 2039-2049.

[19] Koźluk E, Cybulski G, Piątkowska A, Zastawna I, Niewiadomski W, Strasz A, Gąsiorowska A, Kempa M, Kozłowski D, Opolski G. Early hemodynamic response to the tilt test in patients with syncope. Arch Med Sci 2014;10(6):1078-85.

Address for correspondence.

Gerard Cybulski

Institute of Metrology and Biomedical Engineering

Department of Mechatronics

Warsaw University of Technology

Św. Andrzeja Boboli 8

02-525 Warsaw, Poland

G.Cybulski@mchtr.pw.edu.pl 